\title{
Fully Supramolecular Polyrotaxanes as Biphase Drug Delivery Systems
}

\author{
Abdolhossien Massoudi, ${ }^{1}$ Mohsen Adeli, ${ }^{2}$ and Leila Khosravi far ${ }^{1}$ \\ ${ }^{1}$ Department of Chemistry, Payame Noor University, Tehran 19395-4697, Iran \\ ${ }^{2}$ Department of Chemistry, Lorestan University, Khoramabad, Iran
}

Correspondence should be addressed to Leila Khosravi far; avisa.2013@yahoo.com

Received 18 July 2014; Accepted 6 November 2014; Published 2 December 2014

Academic Editor: Qijin Zhang

Copyright (C) 2014 Abdolhossien Massoudi et al. This is an open access article distributed under the Creative Commons Attribution License, which permits unrestricted use, distribution, and reproduction in any medium, provided the original work is properly cited.

Pseudopolyrotaxanes (PPR) consisting of $\alpha$-cyclodextrin rings and polyethylene glycol axes with end thymine groups have been synthesized and characterized successfully. Fluorescein $(\mathrm{Fl})$ as a model drug was conjugated to the hydroxyl functional groups of cyclodextrin rings of PPR via ester bonds and PPR-Fl as the primary drug delivery system was obtained. Finally PPR-Fl was capped by hydrogen bonds between end thymine groups and a suitable complementary molecule such as polycitric acid, citric acid, or adenine. The aim of this work was to control the release of the fluorescein-cyclodextrin (Fl-CD) conjugates, as the secondary drug delivery systems, from PPR-Fl by controlling the noncovalent interactions between stoppers and thymine end groups. It was found that the rate of release of the Fl-CD from PPR-Fl could be controlled by $\mathrm{pH}$ and the ratio of citric acid or adenine to the PPR-Fl.

\section{Introduction}

One of the main objects of nanomedicine is drug delivery by using supramolecular nanostructures [1]. Nanostructures in which building blocks are attached by covalent interactions are not versatile and their structure could not be changed and adapted with different conditions. But building blocks of nanostructures that are assembled by noncovalent interactions could be dissociate or associate easily [2-4]. These properties enable chemists and biologists to predesign and prepare supramolecular nanostructures that change their structure in different biological barriers and adapt themself with these medium to pass them and arrive to the target [5-7].

A type of noncovalent interactions that is used to prepare supramolecular nanostructures excessively is host-guest interactions. Cyclodextrins are one of the most important host molecules in the supramolecular chemistry. Cyclodextrins are naturally occurring products of the degradation of starch by the enzyme glycosyl transferase from Bacillus macerans. The remaining free hydroxyl groups of the glucose moieties are located on the rims of the torus-shaped molecules, rendering them water soluble. The secondary hydroxyl groups, located at C-2 and C-3 of the glucose units are all situated at the broader (on the wider edge of the ring), secondary rim of the molecule, where they form a network of intramolecular hydrogen bonds, providing rigidity to the structure and the primary hydroxyl groups (C6) on the other edge. Apart from these naturally occurring cyclodextrins, many cyclodextrin derivatives have been synthesised. These derivatives usually are produced by aminations, esterifications, or etherifications of primary hydroxyl groups [8]. Recently, cyclodextrin-polymer conjugates are used to construct dendrosomes as biphase drug delivery systems. In these systems, dissociation a usual drug delivery system, dendrosome, leads to a second and smaller drug delivery system [9-11].

Polyrotaxanes (PRs) are highly functional supramolecules consisting of several rings and one or more axes, in which the dissociation of ring from axes is hindered by bulky groups at both ends of the axes. There is no chemical bonding between rings and axes and they are only interlocked physically $[12,13]$. Although polyrotaxanes especially those consisting of polyethylene glycol axis and cyclodextrin rings are used as a biocompatible and multivalent carrier to transport 
gene, drug, and biological active molecules, usually they are left by researchers after one or two reports and they have not been used as therapeutic agents by a group deeply [14, 15].

The two complimentary pairs of nucleobases, adenine with thymine and cytosine with guanosine, have long been considered the key to DNA's stability, replication, and capacity for information storage, with the hydrogen bonds between them playing an integral role. In recent years researchers have begun to probe the importance of these hydrogen bonds and other factors contributing to DNA's intriguing characteristics by replacing base pairs with nonnatural analogs. The use of non-hydrogen-bonded base pair analogs has led to illuminating results which have, and will continue to have, practical impact in many fields including biology, medicine, materials science, supramolecular chemistry, medicinal chemistry, and organic chemistry [16].

Herein we report a new and promising strategy to use PRs as biphase drug delivery systems. In these systems stoppers attached to the end functional groups of PRs could be dissociated by stimuli factors in the biological mediums and the released cyclodextrins make new drug delivery systems by host-guest interactions. In other words dissociation of the rings from axes in PRs led to a large number of small drug delivery systems that could pass biological barriers.

\section{Experimental Section}

2.1. Materials. Polyethylene glycol $(\mathrm{MW}=1000)$ was provided from Fluka (Germany). Thymine, adenine, citric acid, potassium hydroxide, dichloromethane, diethyl ether, triethylamine, $\alpha$-cyclodextrin, dimethylformamide, tosyl chloride, and fluorescein were purchased from Merck (Germany). Dialysis bag (semipermeable membrane cutoff 2000) was obtained from Sigma-Aldrich.

2.2. Instrumentation. ${ }^{1} \mathrm{H}$ nuclear magnetic resonance $\left({ }^{1} \mathrm{H}\right.$ $\mathrm{NMR}$ ) spectra were recorded in $\mathrm{CDCl}_{3}$ and $\mathrm{DMSO}{ }_{-\mathrm{d} 6}$ solvents on a Bruker DRX $400(400 \mathrm{MHz})$ apparatus with the solvent proton signal for reference. The X-ray power diffraction pattern of products was recorded on D8-AdvancedBruker in $2 \theta$ range from $4^{\circ}$ to $75^{\circ}$. A T80 UV-Visible spectrophotometer (PG Instruments Ltd) was used for recording the absorption spectra of samples in solution. Fourier transform infrared (FT-IR) spectra were obtained at a resolution of $1 \mathrm{~cm}^{-1}$ with an Avator 370, Thermo-Nikolt between 4000 and $400 \mathrm{~cm}^{-1}$ using $\mathrm{KBr}$ tablets for solid state and $\mathrm{CH}_{2} \mathrm{Cl}_{2}$ solvent for solution state. Thermogravimetric analysis (TGA) was performed on a Shimadzu, Japan-TGA50 set up under dynamic atmosphere of an inert gas (Ar) at 10 (room temperature to $800^{\circ} \mathrm{C}$ ).

\subsection{Preparation of Ditosylate Polyethylene Glycol (PEG-} diOTs). Ditosylated polyethylene glycol was prepared according to the reported procedure in literature [3]. Briefly PEG (5 g, $5 \mathrm{mmol}$ ) was dissolved in $30 \mathrm{~mL}$ triethylamine and then tosyl chloride $(2.5 \mathrm{~g}, 13.5 \mathrm{mmol})$ dissolved in $15 \mathrm{~mL}$ dichloromethane was added to this solution dropwise. Mixture was stirred at $45^{\circ} \mathrm{C}$ for $8 \mathrm{~h}$. The obtained mixture was filtered and solvent was evaporated, and then it was dissolved in dichloromethane $(100 \mathrm{~mL})$ and precipitated in diethyl ether at $0^{\circ} \mathrm{C}$. The yield was $90 \%$.

IR $v \max / \mathrm{cm}^{-1}$ : $2900(\mathrm{C}-\mathrm{H}), 1100(\mathrm{C}-\mathrm{O}), 1200-1320(\mathrm{~S}=\mathrm{O}$ and S-O), 1500-1600 (Aromatic ring).

${ }^{1} \mathrm{H}$ NMR (400 MHz, $\left.\delta, \mathrm{ppm}\right): 3.6$ (proton of PEG), 7.2-7.7 (Aromatic ring), $2.1\left(\mathrm{CH}_{3}\right.$ of tosylate).

2.4. Functionalization of PEG by Thymine (PEG-diThy). Polyethylene glycol was functionalized by thymine through nucleophilic substitution reaction between PEG-diOTs and thymine. PEG-diOTs ( $2 \mathrm{~g}, 1.5 \mathrm{mmol}$ ) was dissolved in $30 \mathrm{~mL}$ dimethylformamide and then a solution of thymine $(0.5 \mathrm{~g}$, $4.5 \mathrm{mmol})$ and potassium hydroxide $(0.26 \mathrm{~g}, 4.5 \mathrm{mmol})$ in $5 \mathrm{~mL}$ water was added to this solution dropwise. Mixture was refluxed and stirred for $48 \mathrm{~h}$. The obtained mixture was filtered and solvent was evaporated, and then the resultant precipitate was dissolved in dichloromethane $(100 \mathrm{~mL})$ and precipitated in diethyl ether at $0^{\circ} \mathrm{C}$. The yield was $75-80 \%$.

IR $v \max / \mathrm{cm}^{-1}: 1680$ (amidic C=O), 3300 (amidic NH), 2900 (C-H).

${ }^{1} \mathrm{H}$ NMR (400 MHz, $\left.\delta, \mathrm{ppm}\right): 3.71$ (PEG), 11 (amidic NH), $7.25(\mathrm{HC}=\mathrm{C}$ of thymine $), 1.75\left(\mathrm{CH}_{3} \mathrm{C}=\mathrm{C}\right)$.

2.5. Preparation of PPR. For preparation of PPR, $\alpha-\mathrm{CD}$ $(3.75 \mathrm{~g}, 3.85 \mathrm{mmol})$ was dissolved in $10 \mathrm{~mL}$ water to obtain a saturated solution. Then a solution of PEG-diThy ( $1 \mathrm{~g}$, $0.8 \mathrm{mmol}$ ) in $2 \mathrm{~mL}$ water was added to the above suspension with vigorous stirring at $0^{\circ} \mathrm{C}$. The mixture of reaction was stirred at room temperature for $3 \mathrm{~h}$. The obtained white precipitate was filtered and washed by water to remove the excess of $\alpha$-CD and untreated functionalized PEG. The purified product was obtained as a white powder after drying by vacuum oven at $40^{\circ} \mathrm{C}$. The yield was about $80 \%$ (to calculate the amount of $\alpha$-CD of PPR, the amount of the excess of $\alpha$-CD is calculated).

IR $v \max / \mathrm{cm}^{-1}: 1680$ (amidic $\mathrm{C}=\mathrm{O}$ ), 3300 (amidic $\mathrm{NH}$ ), $2900(\mathrm{C}-\mathrm{H}), 3200-3500(\mathrm{OH})$.

${ }^{1} \mathrm{H}$ NMR (400 MHz, $\left.\delta, \mathrm{ppm}\right): 3.71$ (PEG), 3.9-3.5 $(\mathrm{C} 2(\mathrm{H})-\mathrm{C} 6(\mathrm{H})$ of cyclodextrin), $5.1(\mathrm{Cl}(\mathrm{H})$ anomeric proton of cyclodextrin), 11 (amidic $\mathrm{NH}$ ), 7.25 ( $\mathrm{HC}=\mathrm{C}$ of thymine), $1.75\left(\mathrm{CH}_{3} \mathrm{C}=\mathrm{C}\right)$.

2.6. Preparation of Pseudopolyrotaxane-Fluorescein (PPR-Fl). For preparation of PPR-Fl, fluorescein $(3.9 \mathrm{~g}, 12 \mathrm{mmol}$ ) was dissolved in $20 \mathrm{~mL}$ dimethylformamide and then a solution of PPR (2.5 g) and potassium hydroxide $(0.7 \mathrm{~g}, 12 \mathrm{mmol})$ in $5 \mathrm{~mL}$ water was added to this solution with stirring at room temperature for $24 \mathrm{~h}$. The obtained yellow precipitate was filtered and washed by water. The purified product was obtained after drying by vacuum oven at $40^{\circ} \mathrm{C}$. The yield was $70 \%$ (the amount of fluorescein is much more than the amount of $\alpha-\mathrm{CD}$ in order to increase the chance of interactions between fluorescein and 6-OH groups of $\alpha$-CD).

IR $v \mathrm{max} / \mathrm{cm}^{-1}: 1680$ (amidic $\mathrm{C}=\mathrm{O}$ ), 1700 (carbonyl group of fluorescein), 3300 (amidic NH), 2900 (C-H), 3200-3500 $(\mathrm{OH})$. 
${ }^{1} \mathrm{H}$ NMR (400 MHz, $\left.\delta, \mathrm{ppm}\right): 3.71$ (PEG), 3.9-3.5 $(\mathrm{C} 2(\mathrm{H})-\mathrm{C} 6(\mathrm{H})$ of cyclodextrin), $5.1(\mathrm{Cl}(\mathrm{H})$ anomeric proton of cyclodextrin), 6.8-10 (C-H of Aromatic rings of Fluorescein), 11 (amidic NH), $7.25\left(\mathrm{HC}=\mathrm{C}\right.$ of thymine), $1.75\left(\mathrm{CH}_{3}\right.$ $\mathrm{C}=\mathrm{C})$.

2.7. Preparation of PPR-Fl-Citric Acid Supramolecules. For preparation of PPR-Fl-citric acid, PPR-Fl (0.01g) was dissolved in $1 \mathrm{~mL}$ phosphate buffers at $\mathrm{pH} 5.0$ and 7.4 and then a solution of citric acid $(0.01 \mathrm{~g}$ in $1 \mathrm{~mL}$ water $)$ was added to this solution. The mixture was placed on a shaker set at $100 \mathrm{rpm}$ and room temperature for 30 minutes.

2.8. Preparation of PPR-Fl-Polycitric Acid Supramolecules. For preparation of PPR-Fl-polycitric acid, PPR-Fl (0.01 g) was dissolved in $1 \mathrm{~mL}$ phosphate buffers at pH 5.0 and 7.4 and then a solution of polycitric acid $(0.01 \mathrm{~g}$ in $1 \mathrm{~mL}$ water) was added to this solution. The mixture was placed on a shaker set at $100 \mathrm{rpm}$ and room temperature for 30 minutes.

2.9. Preparation of PPR-Fl-Adenine Supramolecules. For preparation of PPR-Fl-adenine, PPR-Fl (0.01 g) was dissolved in $1 \mathrm{~mL}$ phosphate buffers at $\mathrm{pH} 5.0$ and 7.4 and then a solution of adenine $(0.01 \mathrm{~g}$ in $1 \mathrm{~mL}$ water) was added to this solution. The mixture was placed on a shaker set at $100 \mathrm{rpm}$ and room temperature for 30 minutes.

2.10. Dissociation of Supramolecules to Obtain the Secondary Drug Delivery System: The Release Experiment. The prepared supramolecules $(0.02 \mathrm{~g})$ were dissolved in $1 \mathrm{~mL}$ PBS buffer solution ( $\mathrm{pH} 7.4$ and 5) and then purred in a dialysis bag (Mn cutoff 2000). Dialysis bag (Mn cutoff 2000) was then immersed in $50 \mathrm{~mL}$ phosphate buffers ( $\mathrm{pH}=7.4$ and 5 ). Samples with certain volumes were removed from outside solution in intervals times and their UV-visible spectra were recorded. The calibration curve was used to determine the rate of release and concentration of the released fluorescein from supramolecules.

\section{Results and Discussion}

The aim of this work was to synthesise biphase drug delivery systems consisting of a polyrotaxane having thymine end groups and complementary molecules or macromolecules capable to interact with these end groups noncovalently. Fluorescein was conjugated to the hydroxyl functional groups of polyrotaxanes as a model drug. These polyrotaxanes were called primary drug delivery system. Dissociating of the polyrotaxanes under controlled conditions led to cyclodextrinfluorescein conjugates as the secondary drug delivery system.

For preparation of the primary drug delivery system, polyethylene glycol $(\mathrm{Mn}=1000)$ containing end thymine groups was prepared (Scheme 1). End thymine groups as hydrophobic domains increase the favor interactions between polyethylene glycol and cavity of cyclodextrins which leads to pseudopolyrotaxane in a high yield and short time. On the other hand they are containing reactive domains which are able to form hydrogen bonds with complementary molecules or macromolecules such as adenine, citric acid and polycitric acid.

Figure 1 shows the IR spectra of PEG-diOTs, PEGdiThy, PPR, and PPR-Fl. In the IR spectra of PEG-diThy (Figure 1(b)), absorbance band at $3300 \mathrm{~cm}^{-1}$ is assigned to the amidic $\mathrm{NH}$ bond. Disappearance of the absorbance bands of aromatic groups $\left(1500-1600 \mathrm{~cm}^{-1}\right)$ of tosylate groups and appearance of a new absorbance band, assigned to the stretching carbonyl functional group of thymine $\left(1680 \mathrm{~cm}^{-1}\right)$, prove the substitution of tosyl groups by thymine molecules and synthesis of PEG-diThy from PEG-diOTs. In the IR spectra of Ps-PR (Figure 1(c)), absorbance band at $3400 \mathrm{~cm}^{-1}$ is assigned to the stretching vibrations of hydroxyl functional groups of cyclodextrin rings. In the IR spectra of PPR-Fl absorbance band at $1700 \mathrm{~cm}^{-1}$ is assigned to carbonyl groups of fluorescein molecules conjugated to the cyclodextrin molecules through esteric bonds (Figure 1(d)).

Figure 2 shows the ${ }^{1} \mathrm{H}$ NMR spectra of PEG-diOTs, PEG-diThy, PPR, and PPR-Fl. In Figure 2(c), signals of $\alpha$ $\mathrm{CD}$ appeared at 5.5-3 ppm. In this figure signals at 5.5 and $3.6 \mathrm{ppm}$ are assigned to the anomeric proton of cyclodextrin and PEG, respectively. Signals at $1.75,7.25$, and $11 \mathrm{ppm}$ are assigned to the protons of $\mathrm{CH}_{3},-\mathrm{CH}-$, and amidic $-\mathrm{NH}$ groups of thymine. In Figure 2(d), signals of fluorescein appeared at $6.6-10 \mathrm{ppm}$.

Figure 3(a) shows the X-ray pattern of PPR. According to the full width at half-maximum (FWHM) of the diffraction peaks, the average size of the particles can be estimated from the Debye-Scherrer equation:

$$
L=\frac{0.9 \lambda}{B \cos \theta},
$$

where $L$ is the coherent length, $\lambda$ is the wave length of X-ray radiation, $B$ is the full width at half maxima (FWHM) of the prominent peak, and $\theta$ is the angle of diffraction. The relation between $L$ and $D$, the diameter of crystalline, is given by $L=$ $(3 / 4) D$. The corresponding crystallite size of PPR obtained in this way is around $7 \mathrm{~nm}$. The $\mathrm{X}$-ray pattern shows a strong and sharp diffraction peak at $2 \theta=19.6^{\circ}$ which has been known to be a characteristic peak for the channel-type $\alpha$-CD ICs as crystalline materials (the length of $\alpha$-CD is around $0.7 \mathrm{~nm}$ ) [17].

Figure 3(b) shows the TGA diagrams and DTA thermograms for PPR. TGA plot for PPR shows that weight loss occurs in three discrete stages. The first weight loss, about $5 \%$, at $90^{\circ} \mathrm{C}$ corresponds to the removal of water. The second distinct weight loss, about $90 \%$, at $290-400^{\circ} \mathrm{C}$ is due to the decomposition of sample. The third weight loss occurs at 550 $600^{\circ} \mathrm{C}$, about $3 \%$, which is related to the loosing of ending agents. DTA thermogram shows an exothermic peak at $312^{\circ} \mathrm{C}$ that is assigned to the decomposition of PPR.

As it was mentioned before the aim of this work was to prepare biphase drug delivery systems based on fully supramolecular polyrotaxanes. Fluorescein as a model drug was conjugated onto the functional groups of cyclodextrin rings and they were looked by supramolecular interactions (hydrogen bonding) between thymine end groups and complementary molecules such as adenine or citric acid. Then 


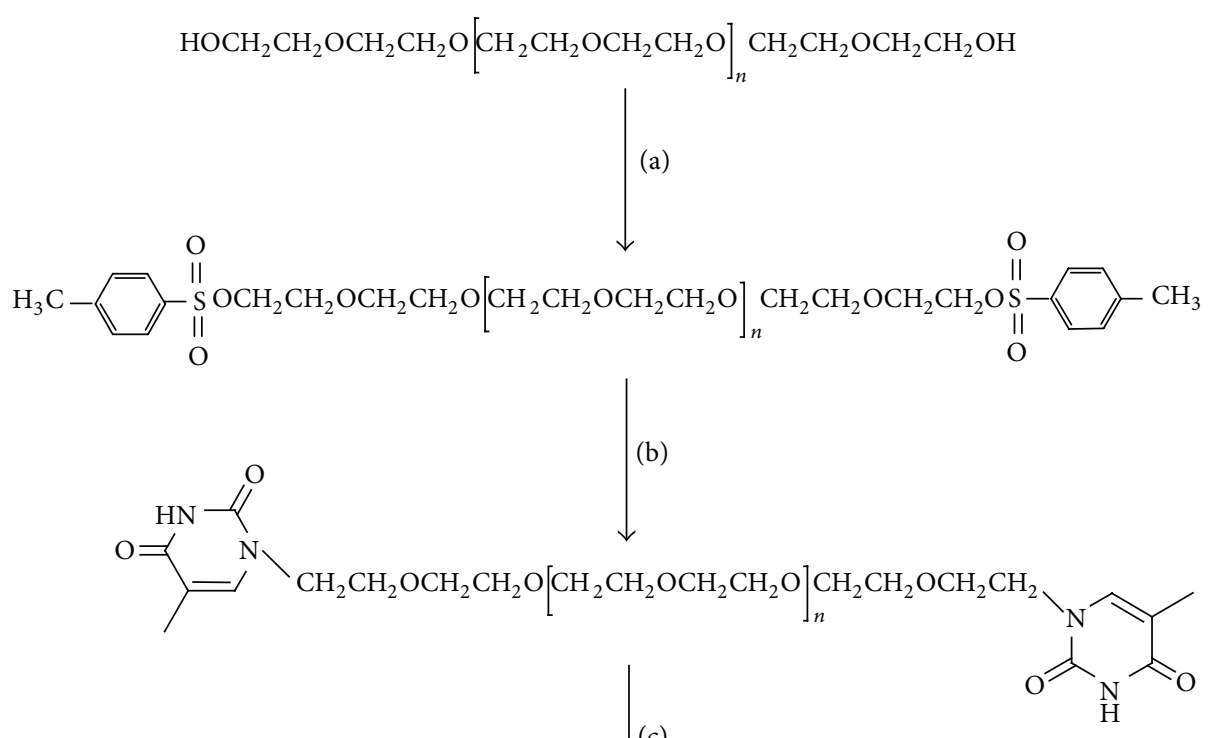

(c)

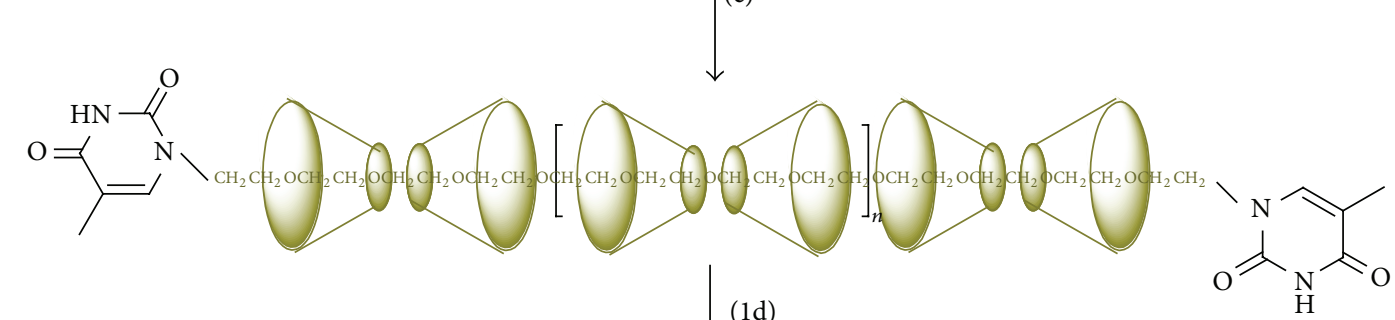

$(2 \mathrm{~d})$

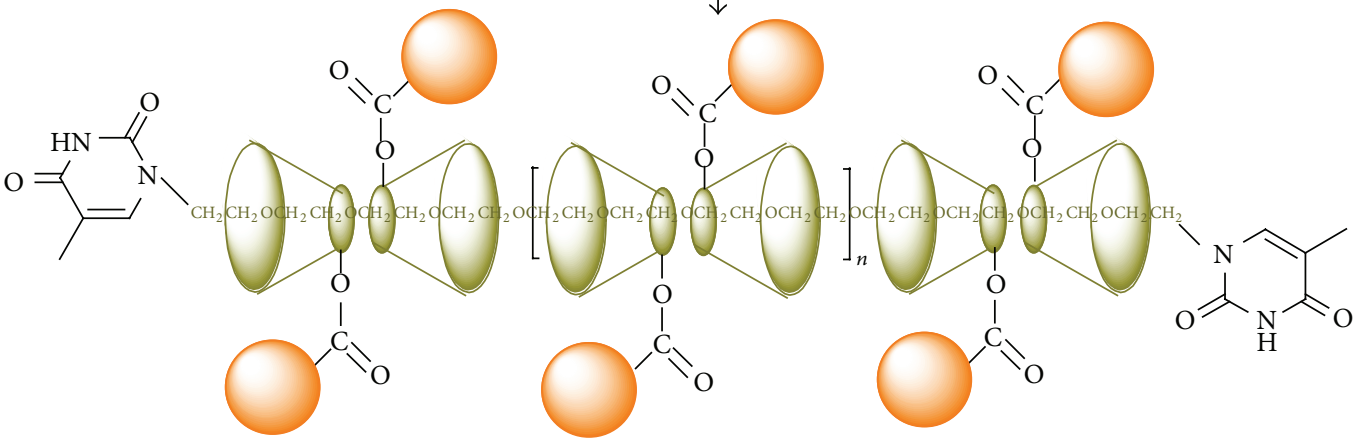

(A)

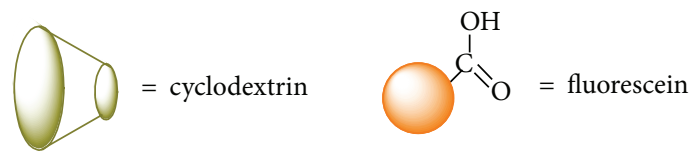

Scheme 1: Representation of the functionalization of polyethylene glycol and synthesis of pseudopolyrotaxane and finally primary drug delivery system. TsCl/ $\mathrm{CH}_{2} \mathrm{Cl}_{2} / \mathrm{NEt}_{3} / 45^{\circ}$ (a), thymine/KOH$/ \mathrm{DMF} / \mathrm{H}_{2} \mathrm{O} / 2$ days $/ 70^{\circ}$ (b), cyclodextrin $/ \mathrm{r} . \mathrm{t} / 3 \mathrm{~h}$ (c), $\mathrm{KOH} / \mathrm{H}_{2} \mathrm{O}$ (1d), fluorescein/DMF/24 h/r.t (2d).

the ability of these weak interactions to avoid dissociation of the cyclodextrin-fluorescein conjugated as the secondary drug delivery system from polyrotaxane as the primary drug delivery system was investigated (Figure 4).

Figure 4 shows UV-Vis spectra of PPR-FI and this system capped with adenine, citric acid, and polycitric acid. As it can be seen PPR-FI and this system capped with adenine show a maximum absorption centered around $475 \mathrm{~nm}$. The peaks at $470 \mathrm{~nm}$ are characteristic of highly conjugated aromatic molecules like fluorescein and anthracene. However in the case of systems that are capped by citric acid and polycitric acid a blue shift for this peak is observed. It is reasonable to infer that the strong interactions between carbonyl groups of fluorescein and hydroxyl groups of citric acid and polycitric 


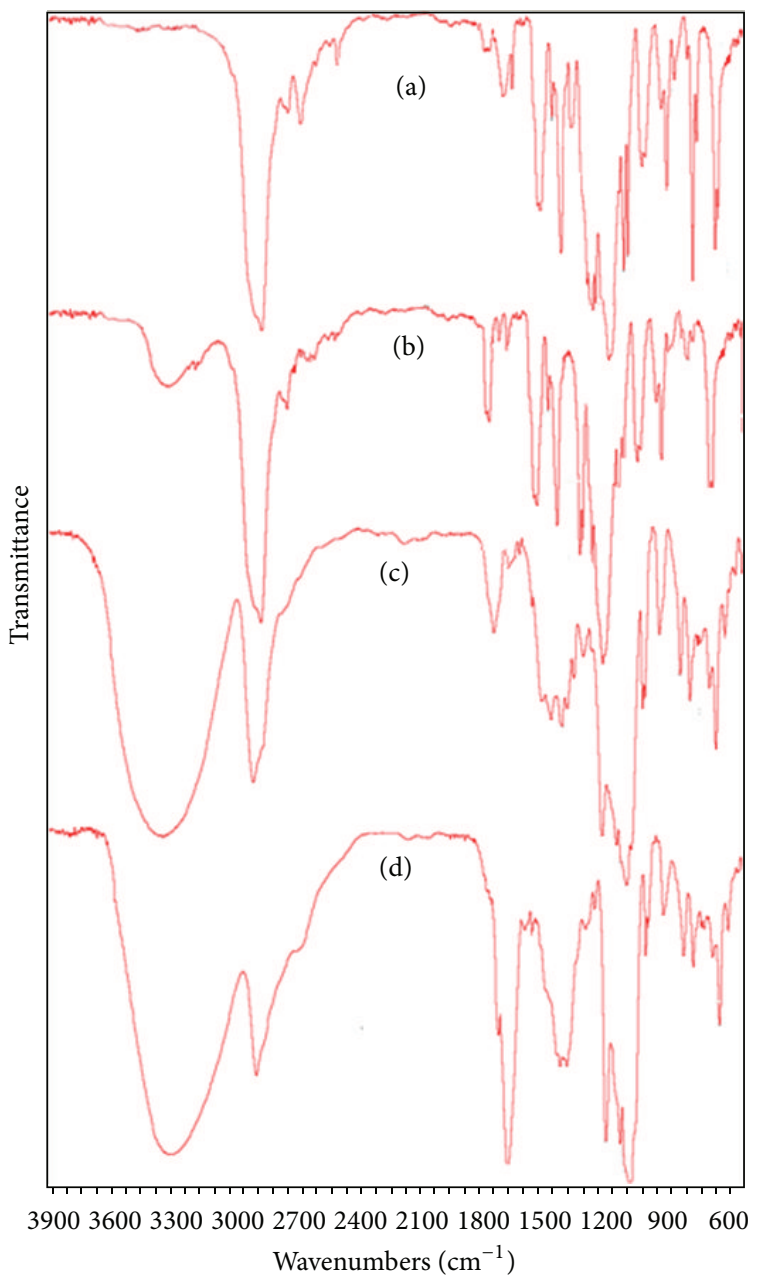

FIGURE 1: IR spectra of PEG-diOTs (a) in $\mathrm{CH}_{2} \mathrm{Cl}_{2}$, PEG-diThy (b) in $\mathrm{CH}_{2} \mathrm{Cl}_{2}$, Ps-PR (c) using KBr tablet, and PPR-Fl (d) using KBr tablet.

TABLE 1

\begin{tabular}{lc}
\hline Molecule & $\lambda(\mathrm{nm})$ \\
\hline PPR-FI & 472 \\
PPR-FI \& adenine & 475 \\
PPR-FI \& citric acid & 435 \\
PPR-FI \& polycitric acid & 437 \\
\hline
\end{tabular}

acid increase the energy difference between the corresponding relative HOMO and LUMO, so a blue shift for this peak occurs (see Table 1).

In order to investigate the ability of the end thymine groups to create hydrogen bonds with the complementary molecules, IR spectra of thymine and its mixtures with these molecules were recorded. Figure 5(c) shows IR spectra of thymine-adenine mixture ( $1 / 1$ molar ratio) in aqueous solution and at room temperature. Figure 5(e) shows the same spectra in the same condition for citric acid-thymine mixture (1/1 molar ratio). As it can be seen patterns for absorbance bands of functional groups of adenine and citric acid are

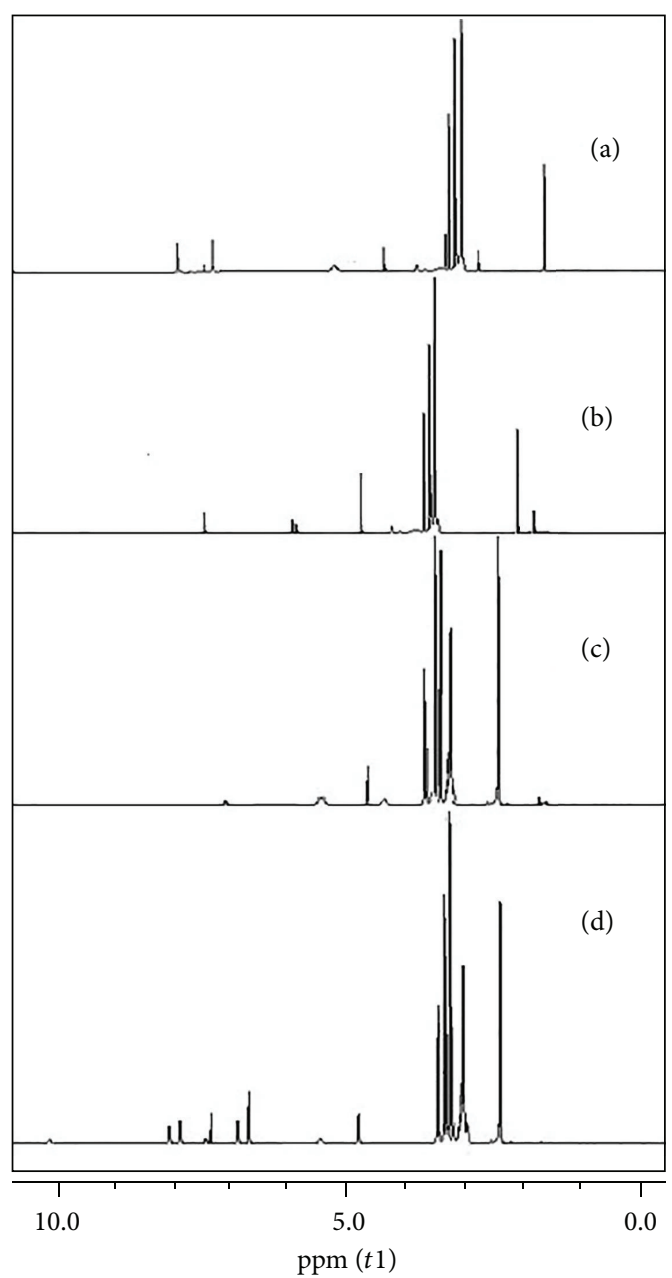

FIGURE 2: ${ }^{1} \mathrm{H}$ NMR spectra of PEG-diOTs (a) in $\mathrm{CDCl}_{3}$, PEG-diThy (b) in $\mathrm{CDCl}_{3}, \mathrm{PPR}$ (c) in $\mathrm{DMSO}_{-\mathrm{d} 6}$, and PPR-Fl (d) in $\mathrm{DMSO}_{-\mathrm{d} 6}$.

changed when mixed with adenine dramatically. In both mixtures absorbance bands of the hydroxyl, $\mathrm{N}-\mathrm{H}$, and carbonyl groups are shifted and board upon mixing with thymine in comparison with their individual components. This result confirms that thymine associates with adenine and citric acid by hydrogen bonds, although aqueous solutions are not optimal places to create hydrogen bonds.

Figure 6 shows the accumulative release percent of fluorescein-cyclodextrin conjugate (the secondary drug delivery system) from the primary drug delivery system when it is not capped and capped by citric acid, polycitric acid, and adenine complementary molecules or macromolecules in the buffer at $\mathrm{pH}=7.4$. As it can be seen the rate of release of the secondary drug delivery system from the primary drug delivery system is high and around $100 \%$ of this system release in four hours when it is not capped by any complementary molecule. However when systems are capped by supramolecular interactions the rate of release decreases and they show a slow release. The slowest release is shown when polyrotaxane is capped by citric acid. In order to investigate the role of citric acid on the rate of release of secondary drug delivery system, two weight ratios of citric acid for capping of polyrotaxane 


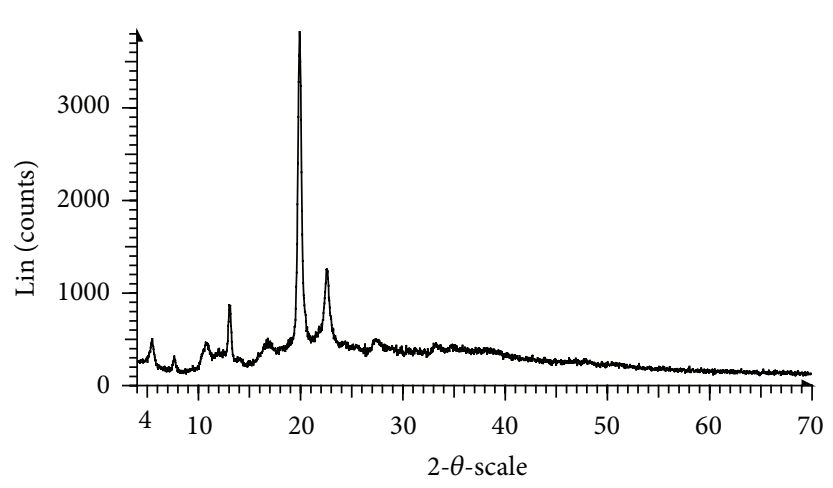

(a)

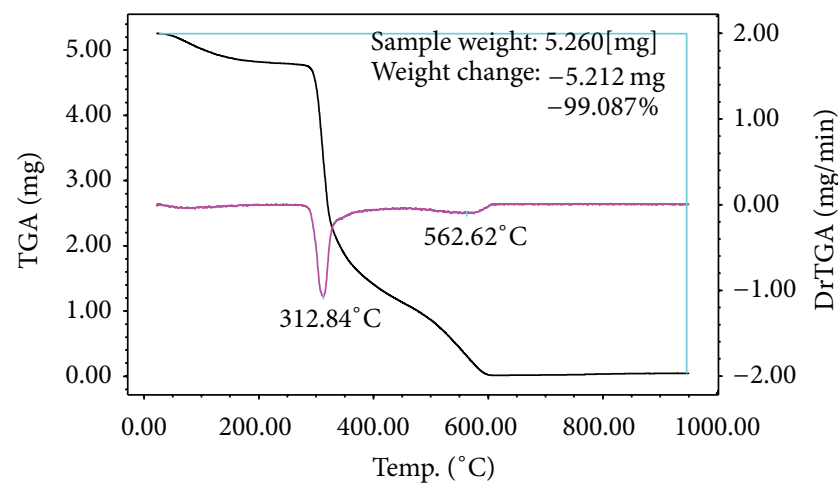

(b)

Figure 3: (a) XRD pattern of PPR; (b) TGA of PPR.

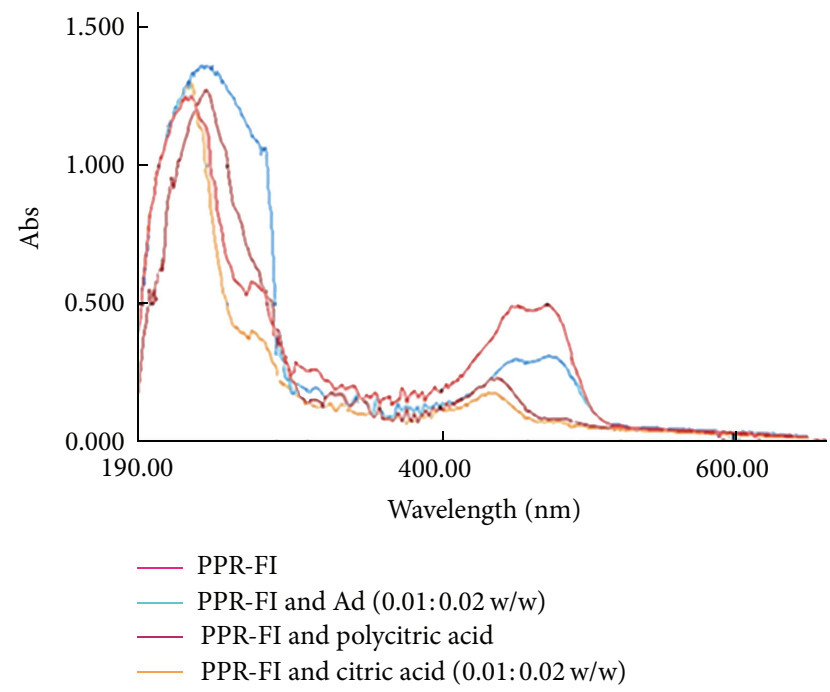

FIGURE 4: UV-Vis spectra of PPR-Fl, and this system capped by adenine, citric acid, and polycitric acid in PBS buffer and at room temperature.

have been used. As it can be seen when the weight ratio of citric acid to polyrotaxane increases two times ( 0.01 versus $0.02 \mathrm{~W} / \mathrm{W}$ ) the rate of release decreases slightly, proving that the $0.01 \mathrm{~W} / \mathrm{W}$ ratio of citric acid is enough to make strong interaction with thymine end groups of polyrotaxane and locked secondary drug delivery systems sufficiently and finally avoiding a fast release. The second best agent that is able to stop cyclodextrin-fluorescein conjugates and decrease their rate of release sufficiently is polycitric acid. However the rate of release is higher than citric acid due to the steric hindrance between carboxyl functional groups of polycitric acid that leads to weaker supramolecular interactions with active sites of thymine. Interestingly adenine cannot stop the release of secondary drug delivery systems from polyrotaxane sufficiently, due to the weaker hydrogen bonds probably.

Figure 7 shows the same release experiments from the same systems but in PBS buffer with pH 5. Herein the rate of release of the secondary drug delivery systems from the

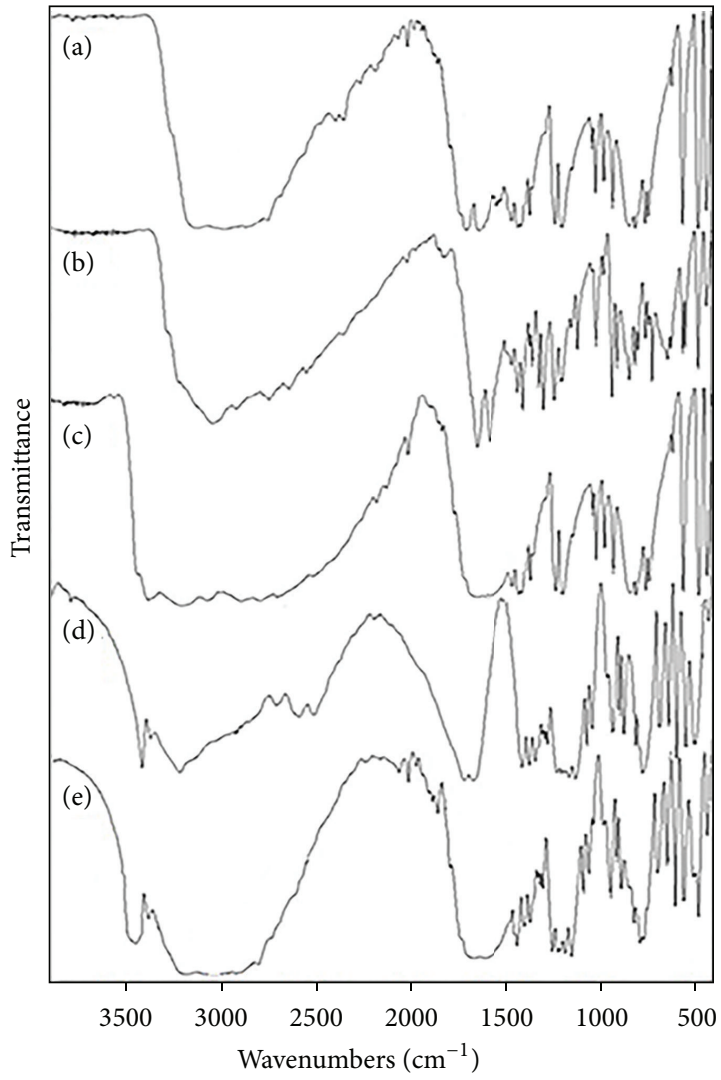

FIGURE 5: IR spectra of (a) thymine, (b) adenine, (c) thymineadenine, (d) citric acid, and (e) thymine-citric acid.

primary drug delivery system increases for all systems dramatically in comparison with that in $\mathrm{pH}$ 7.4. However the rate of release for systems that are capped by citric acid or polycitric acid is still slower than other systems. It can be found that the supramolecular systems are highly sensitive to change in the medium factors such as $\mathrm{pH}$. Since one of the main differences between cancerous and normal tissues is $\mathrm{pH}$, the reported supramolecules are promising systems in order to passive targeting therapeutic agents to target places in the body. 


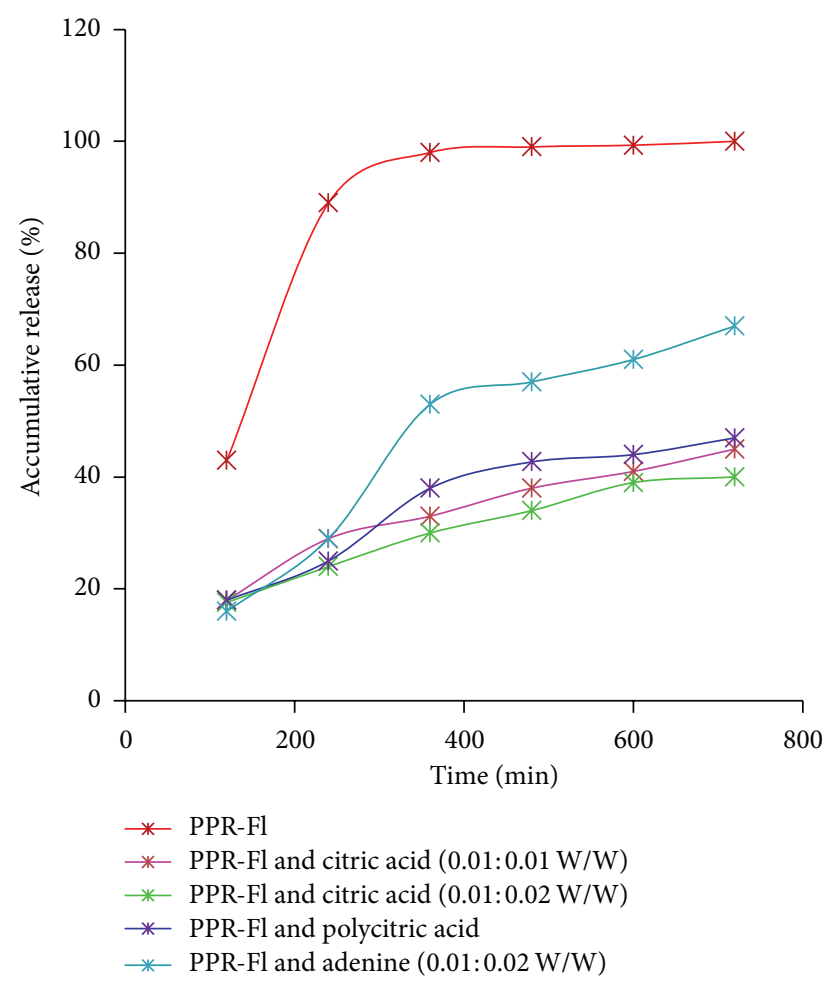

FIGURE 6: The rate of release of the secondary drug delivery system (cyclodextrin-fluorescein conjugates) from the primary drug delivery system in $\mathrm{pH} 7.4$.

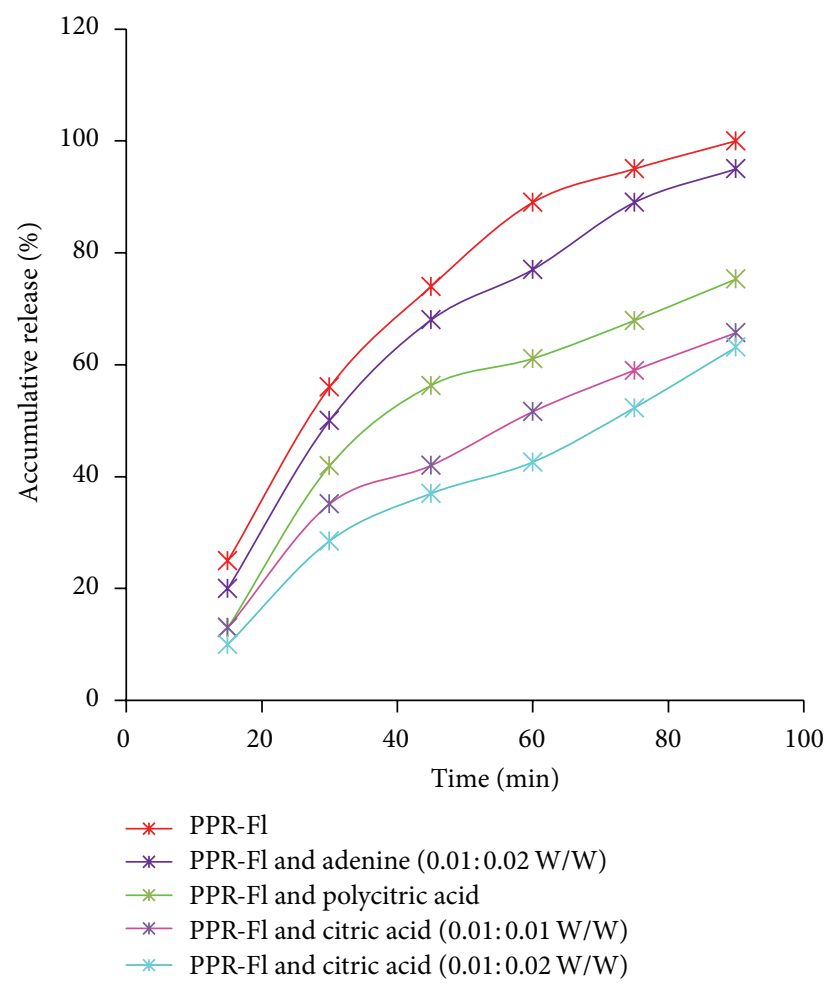

FIGURE 7: The rate of release of the secondary drug delivery system (cyclodextrin-fluorescein conjugates) from the primary drug delivery system in $\mathrm{pH} 5$. 


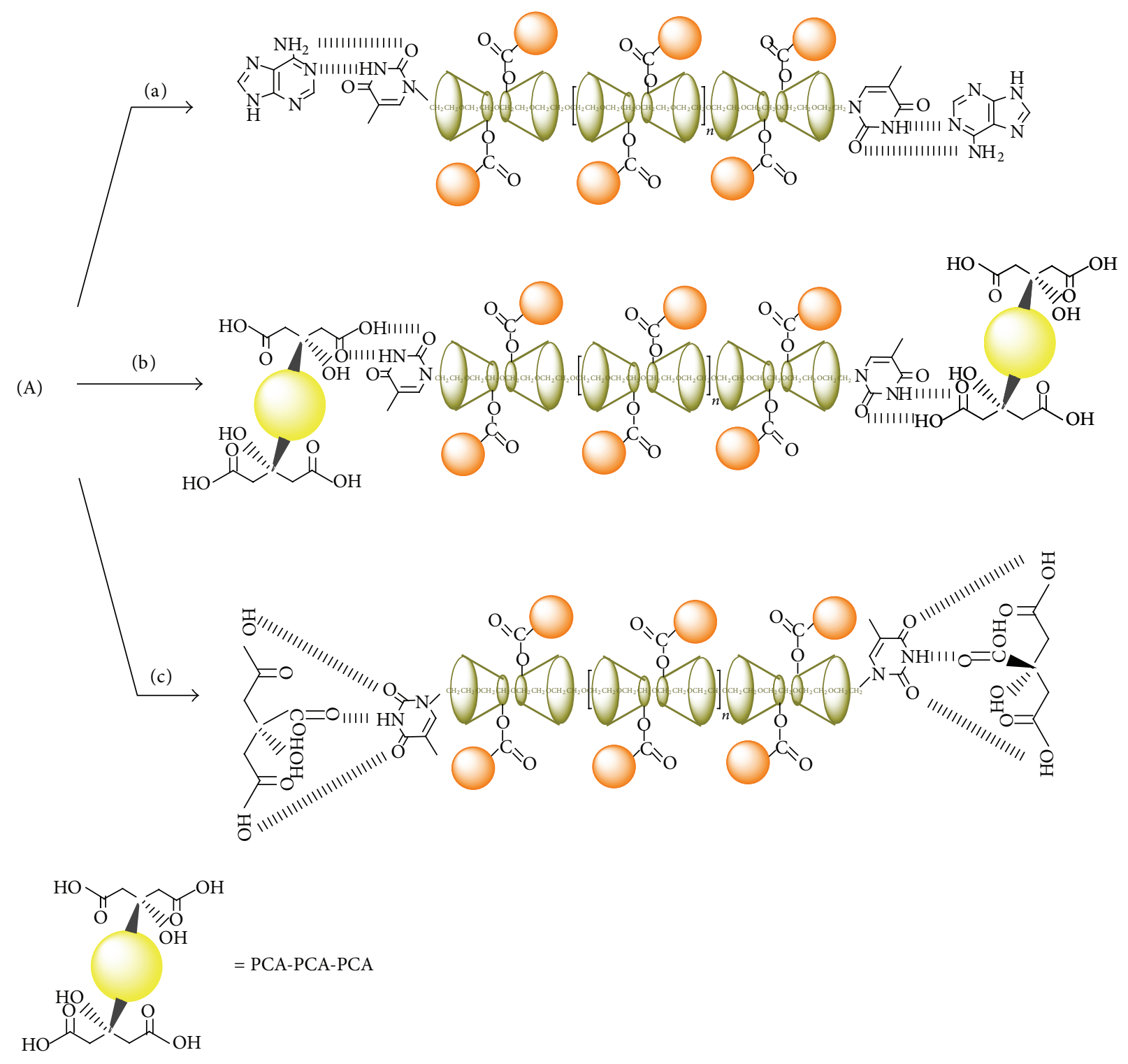

Scheme 2: Interactions between PPR and adenine (a), PCA-PEG-PCA (b), and citric acid (c).

However the released agents that are released in the targeted tissue are not individual therapeutic agents. They are secondary drug delivery systems with small sizes which have been created from a system with bigger size. Due to their small sizes and also carbohydrate backbone of the secondary drug delivery systems they will cross the cell membrane as usual drug delivery systems probably.

As a result the rate of release or the secondary drug delivery systems can be controlled and regulated by the type of stopper or its ratio (Scheme 2).

\section{Conclusion}

Fully supramolecular polyrotaxanes were prepared and used as biphase drug delivery systems. Release of the secondary drug delivery systems from the primary drug delivery system was controlled by stimuli factors such as $\mathrm{pH}$. Due to the versatility of the supramolecular interactions between capping agents and pseudopolyrotaxanes, they are promising systems to deliver therapeutic agents such as anticancer drugs to target tissues.

\section{Conflict of Interests}

The authors declare that there is no conflict of interests regarding the publication of this paper.

\section{References}

[1] A. Harada, A. Hashidzume, H. Yamaguchi, and Y. Takashima, "Polymeric rotaxanes," Chemical Reviews, vol. 109, no. 11, pp. 5974-6023, 2009.

[2] X. Zhang, L. Meng, Q. Lu, Z. Fei, and P. J. Dyson, “Targeted delivery and controlled release of doxorubicin to cancer cells 
using modified single wall carbon nanotubes," Biomaterials, vol. 30, no. 30, pp. 6041-6047, 2009.

[3] S. Rannard and A. Owen, "Nanomedicine: not a case of "One size fits all'”' Nano Today, vol. 4, no. 5, pp. 382-384, 2009.

[4] A. Harada and M. Kamachi, "Complex formation between poly(ethylene glycol) and $\alpha$-cyclodextrin," Macromolecules, vol. 23, no. 10, pp. 2821-2823, 1990.

[5] C. Wang, J. Chen, T. Talavage, and J. Irudayaraj, "Gold nano$\mathrm{rod} / \mathrm{Fe}_{3} \mathrm{O}_{4}$ nanoparticle "nano-pearl-necklaces" for simultaneous targeting, dual-mode imaging, and photothermal ablation of cancer cells," Angewandte Chemie, vol. 48, no. 15, pp. 27592763, 2009.

[6] J. H. Choi, K. H. Chen, J.-H. Han, A. M. Chaffee, and M. S. Strano, "DNA aptamer-passivated nanocrystal synthesis: a facile approach for nanoparticle-based cancer cell growth inhibition," Small, vol. 5, no. 6, pp. 672-675, 2009.

[7] J. D. Byrne, T. Betancourt, and L. Brannon-Peppas, "Active targeting schemes for nanoparticle systems in cancer therapeutics," Advanced Drug Delivery Reviews, vol. 60, no. 15, pp. 1615-1626, 2008.

[8] M. V. Rekharsky and Y. Inoue, "Complexation thermodynamics of cyclodextrins," Chemical Reviews, vol. 98, no. 5, pp. 1875-1917, 1998.

[9] R. S. Sarabi, E. Sadeghi, H. Hosseinkhani, M. Mahmoudi, M. Kalantari, and M. Adeli, "Polyrotaxane capped quantum dots as new candidates for cancer diagnosis and therapy," Journal of Nanostructured Polymers and Nanocomposites, vol. 7, no. 1, pp. 18-31, 2011.

[10] Y. Zhou, X. Fan, W. Zhang, D. Xue, and J. Kong, "Stimuliinduced gel-sol transition of supramolecular hydrogels based on $\beta$-cyclodextrin polymer/ferrocene-containing triblock copolymer inclusion complexes," Journal of Polymer Research, vol. 21, no. 2, article 359, 2014.

[11] M. Adeli, A. K. Fard, F. Abedi, B. K. Chegeni, and F. Bani, "Thermo- and pH-sensitive dendrosomes as bi-phase drug delivery systems," Nanomedicine: Nanotechnology, Biology, and Medicine, vol. 9, no. 8, pp. 1203-1213, 2013.

[12] J. Wu, H. He, and C. Gao, " $\beta$-Cyclodextrin-capped polyrotaxanes: one-pot facile synthesis via click chemistry and use as templates for platinum nanowires," Macromolecules, vol. 43, no. 5, pp. 2252-2260, 2010.

[13] J. Han and C. Gao, "Host-guest supramolecular chemistry of dendritic macromolecules," Current Organic Chemistry, vol. 15, no. 1, pp. 2-26, 2011.

[14] M. Osaki, Y. Takashima, H. Yamaguchi, and A. Harada, "Nanospheres with polymerization ability coated by polyrotaxane," Journal of Organic Chemistry, vol. 74, no. 5, pp. 1858-1863, 2009.

[15] A. T. Naeini, M. Adeli, and M. Vossoughi, "Poly(citric acid)block-poly(ethylene glycol) copolymers-new biocompatible hybrid materials for nanomedicine," Nanomedicine: Nanotechnology, Biology and Medicine, vol. 6, no. 4, pp. 556-562, 2010.

[16] K. M. Guckian, J. C. Morales, and E. T. Kool, "Structure and base pairing properties of a replicable nonpolar isostere for deoxyadenosine," The Journal of Organic Chemistry, vol. 63, no. 26, pp. 9652-9656, 1998.

[17] R. Yuan and X. Shuai, "Supramolecular micellization and pHinducible gelation of a hydrophilic block copolymer by blockspecific threading of $\alpha$-cyclodextrin," Journal of Polymer Science, Part B: Polymer Physics, vol. 46, no. 8, pp. 782-790, 2008. 

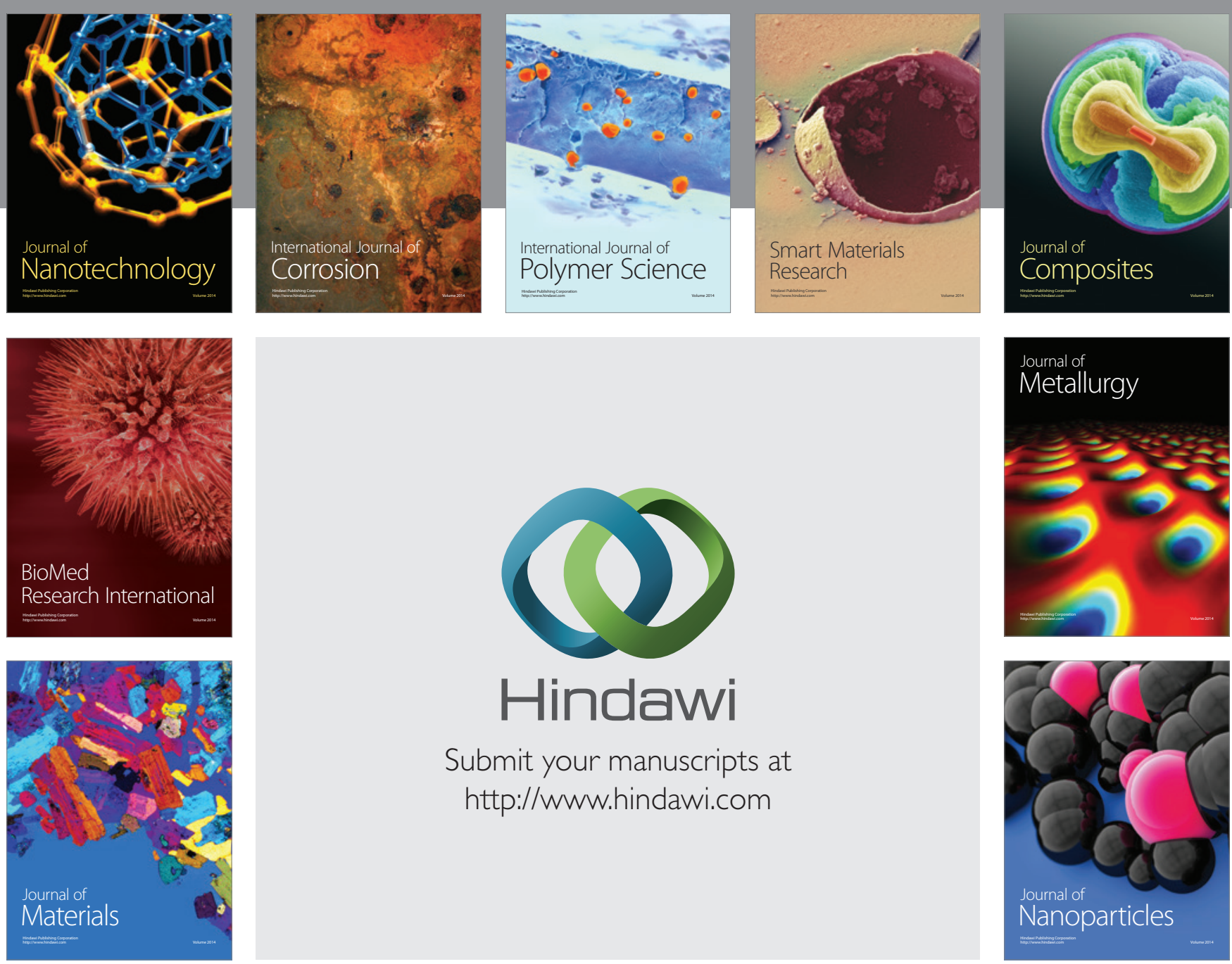

Submit your manuscripts at http://www.hindawi.com
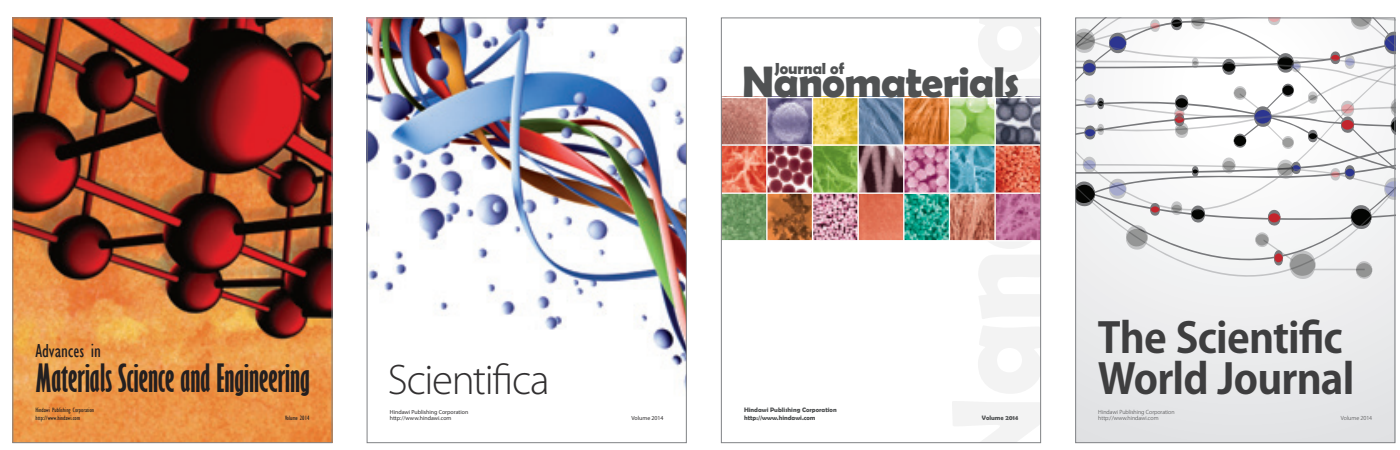

\section{The Scientific World Journal}
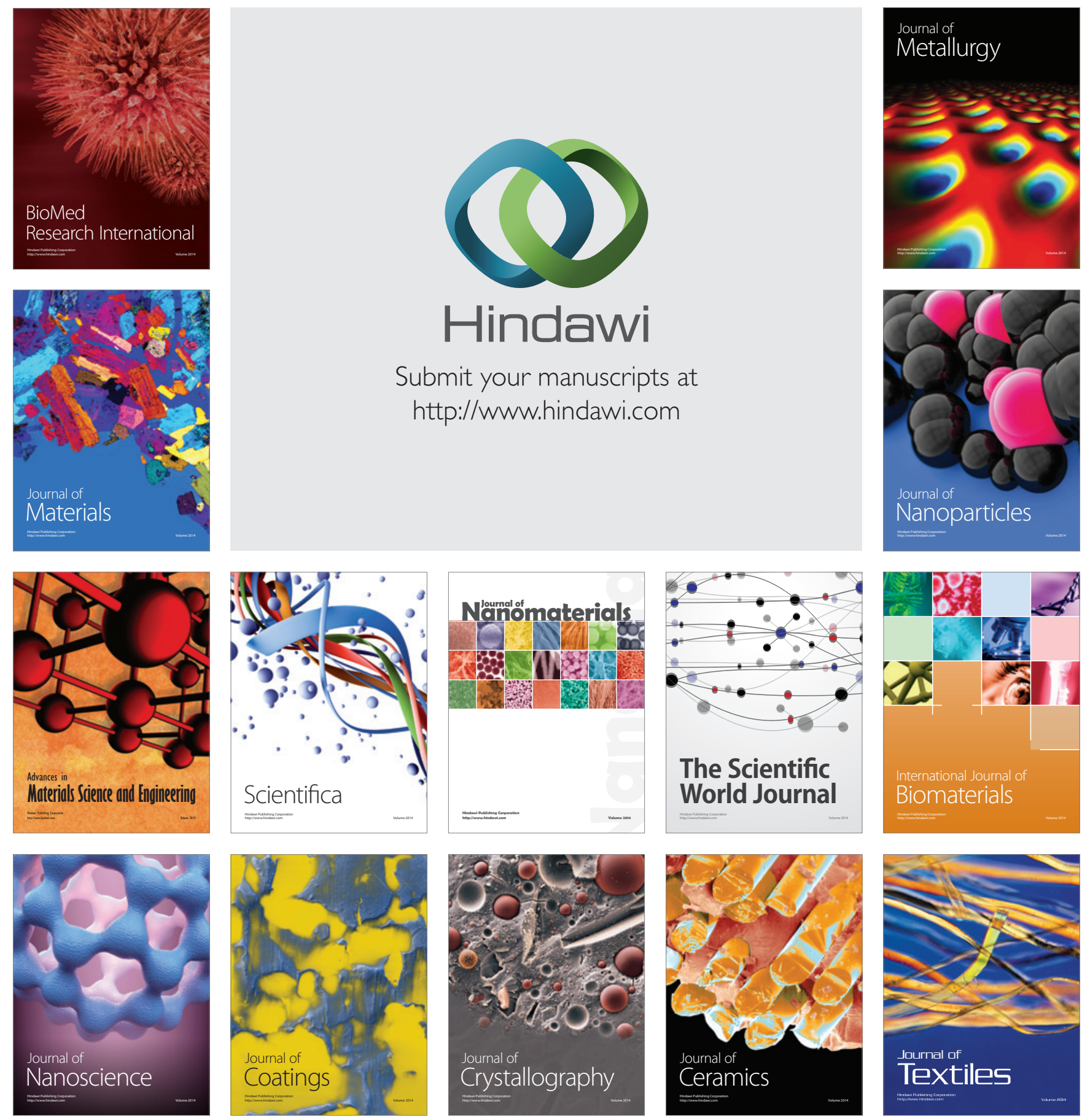